underdeveloped concerning the necessary number of staff members. These conditions have necessitated considerable limitations in the documentation programme. Our case history certainly includes the physical deficit by means of the classic neurological status and the conditions of joint, skin and urinary tract. For judging disability and future work-capacity we use a fairly simple pattern which can be applied to different impairments and is easily transferable to a IBM punch card.

We hope, that these data might be a modest step towards a prognostic evaluation of future chances for our patients.

\title{
A MODEL FOR DOCUMENTATION OF SPINA BIFIDA
}

\author{
By Klausdieter Parsch, M.D. \\ Orthopaedic University Clinic, Spinal Injuries Centre, \\ Heidelberg, Germany
}

FOURTEEN months ago we opened a special ward for the habilitation of paraplegic children with the orthopaedic university clinic of Heidelberg. Already within the first few months of our work it became evident that we would be mainly concerned with the treatment of congenital paraplegia on account of the prevailing number of children.

Only few children with myelomeningocele had been treated in our clinic before we opened a special ward. The outcome of our habilitative efforts was limited by the extent of the neurological defect. We got satisfactory results with sacral lesions having neurogenic foot deformities. On the other hand the results of treatment in myelomeningocele with lumbar or thoracic lesions at that time were as a rule inadequate.

An important impulse was received at a joint meeting in Heidelberg last summer with Mr Sharrard and Dr. Lorber from Sheffield. In the meantime we have habilitated 20 children with spina bifida cystica. Nevertheless, the waiting list for children to be operated or trained is steadily increasing. Since January I969 we have opened a special spina bifida out-patient day, where a team of a doctor, a physiotherapist and a social worker see three to five new cases every week. Most of these children had been without an adequate orthopaedic treatment before.

Dealing with these problems, particularly new in Germany, we were confronted very soon with the necessity of a sufficient documentation of the possible causes and clinical findings. The complexity of pathological symptoms makes a co-ordinated programme necessary among the teams concerned: neuro-surgeon, pediatrician, neurologist, orthopaedic surgeon, urologist, psychologist, educational officer, etc. The distance of several miles between the orthopaedic clinic where we are working and the other clinics has been a handicap for co-ordination, but during the last months the co-operation has considerably improved by exchange of clinical records and joint meetings.

At first we used a double-sided form in which we recorded the family history and the course of pregnancy and birth. This form also included columns of neurological, neurosurgical and urological facts of interest. The clinical findings were recorded according to orthopaedic aspects with special reference to neurology. As the number of children coming as out-patients and for clinical treatment is 
increasing steadily, we have come to realize that it is of greatest importance to work out a common and comprising key of documentation.

Our contribution is a proposal for the establishment of the patient's history as well as the clinical report suitable for the computer. Naturally the orthopaedic point of view is emphasised in our proposal. We would like to co-ordinate our programme with that of other specialists concerned so that we would be able to develop a common documentation system within the followingmonths. This would give us the possibility to survey the whole material in a more systematic way, which would certainly be of great help to establish more special units for the treatment and habilitation of children with spina bifida. In our opinion this seems to be of great importance, especially for countries without national registration of congenital malformations.

Our system is based on the usual punch-card form with 80 columns on each card. Dates of general interest such as date of birth, age, sex, twins, etc., are set down in the first columns. Sixty-one columns are left on each card for the special history and the clinical report. From our experience we learned to restrict the documentation to some few cards otherwise the wishes of trained specialists could jeopardise the whole system.

We hope to be able to improve and correct our attempted documentation system to hand it over to other clinics and special centres.

\section{Discussion}

Chairman. Thank you Dr. Parsch for your detailed report on this subject of paraplegia-spina bifida-which is of increasing importance. Some years ago we discussed this problem in one of our Scientific Meetings not only with regard to the paralysis as such but with regard to the deformity and other complications which can be avoided by an early and proper management. I do congratulate Dr. Paeslack that he has set up a special ward for these children as Dr. Gregg has done in Dublin and who will give us a paper on the subject. I am quite convinced that this will result in promoting new and important knowledge in our work. We started at Stoke Mandeville in the early 50's to treat spina bifida cases which we got at that time from Dr. Barnardo's Home in terrible conditions due to initial mismanagement. If, from a social point of view, we want to help these children and prevent them from developing into hopeless paraplegics later, I think the answer must be that every spinal injuries unit should have a special department for this kind of patient.

I now open the general discussion.

Dr. Young (U.S.A.). (No detail of his remarks available.) Dr. Young reported about the book on classification of diseases as compiled by the International World Health Organization. He stressed the shortcomings of this book and suggested that this book should be revised as soon as possible as far as paraplegia and rehabilitation is concerned.

Chairman. We have discussed the value of this book previously and I think we are all unanimous that this is an unsatisfactory document and unless revised no computer will help us to classify our subject according to this book. I think the time has come that our American colleagues should take steps to revise the whole thing. As Dr. Young quite rightly said, he cannot talk for the U.S. at large because there are so many and everybody has his own classification. 